Jurnal Geocelebes Vol. 5 No. 2, Oktober 2021, 182 - 188

\title{
ANALISIS KARAKTERISTIK ARUS DI PERAIRAN TELUK PAREPARE, SULAWESI SELATAN
}

\author{
Sri Ningsih ${ }^{1 *}$, Bergita Gela M. Saka ${ }^{2}$ \\ ${ }^{1}$ Jurusan Teknik Sipil, Universitas Muhammadiyah Luwuk Banggai, Indonesia. \\ ${ }^{2}$ Jurusan Pendidikan Fisika, Universitas Kristen Indonesia Toraja, Indonesia. \\ *Corresponding author. Email: sriningsih.jmfaperta03@gmail.com
}

Manuscript received: 1 January 2020*); Received in revised form: 22 September 2021; Accepted: 27 October 2021

\begin{abstract}
Abstrak
Perairan Teluk Parepare merupakan teluk semi-tertutup, beberapa titik tertentu terdapat submarine canyon (kontur yang menjorok ke dalam) yang secara viskositas dinilai dapat mempengaruhi pola sirkulasi arus laut yakni vektor dan magnitude-nya. Penelitian ini bertujuan untuk mengetahui pola arus dan kecepatan arus pasang surut yang disebabkan oleh karakteristik kedalaman di perairan Parepare. Metode penelitian menggunakan analisis deskriptif kualitatif. Sementara analisis hidrodinamika menggunakan software SMS (Surface Water Modelling System) dengan sub-program RMA-2 yang diturunkan dari persamaan beda hingga 2D. Hasil penelitian menunjukkan bahwa kondisi perairan di Teluk Parepare pada waktu-waktu tertentu terjadi rotasi arus dan pertemuan arus yang disebabkan oleh variasi kedalaman dan adanya perubahan kecepatan. Perubahan dari kecepatan yang tinggi 0,068 -0,21 $\mathrm{m} / \mathrm{s}$ ke kecepatan yang cukup rendah $0,0029-0,0051 \mathrm{~m} / \mathrm{s}$. Pada daerah submarine canyon (kontur yang menjorok ke dalam), pola arus membentuk pusaran (turbulensi) dengan kecepatan rata-rata berkisar $0,031 \mathrm{~m} / \mathrm{s}$. Sehingga dapat dikatakan bahwa tipe kontur kedalaman dapat mempengaruhi pola arus di perairan Teluk Parepare. Karakteristik kondisi arus pada saat musim barat (hujan) kecepatan arus lebih besar dan lebih fluktuatif (tidak stabil) dibandingkan dengan kecepatan arus rata- rata pada musim timur (kemarau).
\end{abstract}

Kata Kunci: kontur kedalaman; SMS; Teluk Parepare.

\begin{abstract}
The waters of the Parepare Bay are semi-closed bays that at certain points have submarine canyons (contours that protrude into the inside) viscosity which are considered to be able to affect the circulation pattern of ocean currents namely the vector and its magnitude. This study aims to determine the pattern of currents and tidal currents caused by depth characteristics in Parepare waters. The research method uses descriptive qualitative analysis. While hydrodynamic analysis uses SMS (Surface Water Modeling System) software with RMA-2 sub program derived from difference equation to $2 \mathrm{D}$. The results showed that the condition of the water in Parepare Bay at certain times there was a current rotation and flow of currents caused by variations in-depth and speed changes. The change from a high speed of $0.068-$ $0.21 \mathrm{~m} / \mathrm{s}$ to a fairly low speed of $0.0029-0.0051 \mathrm{~m} / \mathrm{s}$. In the submarine canyon area (contour that protrudes inward), the current pattern forms a vortex (turbulence) with an average speed of around 0.031 $\mathrm{m} / \mathrm{s}$. So it can be said that the type of depth contour can affect the current pattern in Parepare Bay waters. Characteristics of current conditions during the west season (rainy), the current velocity is greater and more volatile (unstable) compared to the average current velocity in the east season (dry).
\end{abstract}

Keywords: depth contour; Parepare Bay; SMS. 


\section{Pendahuluan}

Teluk Parepare merupakan salah satu teluk yang berbatasan secara langsung dengan Selat Makasar, sehingga kondisi perairan di Teluk Parepare sangat berkaitan dengan mekanisme sirkulasi di Selat Makasar. Selat Makassar merupakan salah satu wilayah perairan yang sensitif terhadap perubahan iklim dan proses dinamika laut. Perairan Selat Makasar sering terjadi proses mixing atau turbulensi yang digenerasi oleh gaya pasang surut dan pengaruh ENSO ( $E l$ Nino-Southern Oscillaton) (Wisha dan Heriati, 2016).

Teluk Parepare memiliki karakteristik perairan semi-tertutup dan terlindung dari pengaruh angin dan gelombang. Sehingga lingkungan perairan memiliki energi kecil. Selanjutnya Teluk Parepare di bagian timur laut mendapat suplay sedimen dari Sungai Karaja'e. Sehingga dinilai transport sedimen sungai dapat mempengaruhi karakteristik kontur kedalaman teluk. Ditambah lagi relatif tingginya pembangunan di sekitar pesisir yang memicu endapan total sedimen tersuspensi (TSS) di spot area area tertentu. Hal ini sesuai dengan Resources Management Associates-2 (RMA) yang mampu menghitung perubahan elevasi permukaan perairan dan komponen kecepatan arus horizontal untuk aliran permukaan bebas sub-kritis dalam medan aliran dua dimensi.

Pada dasarnya modul ini menyelesaikan masalah aliran turbulen Persamaan Reynolds yang diturunkan dari Persamaan Navier-Stokes. Pengaruh kekasaran diperhitungkan dengan Koefisien Manning atau Chezy, sementara karakteristik turbulensi diperhitungkan dengan memasukkan koefisien kekentalan turbulen (eddy viscosity). Baik masalah steady flow maupun unsteady flow dapat diselesaikan dengan baik.

Karakteristik kontur kedalaman Teluk Parepare yang demikian sehingga penelitian ini dilakukan, yakni menganalisis karakateristik arus perairan Teluk Parepare berdasarkan kedalaman. Arus yang disebabkan oleh pasang surut.

\section{Metode Penelitian}

Penelitian dilakukan pada Mei 2019 dengan lokasi berada di Teluk Parepare. Data yang digunakan adalah data sekunder, yaitu data pasang surut, data kedalaman (bathimetri), dan data kecepatan arus hasil pengukuran.

Metode penelitian yang digunakan adalah metode deskriptif kualitatif dan kuantitatif. Analisis data menggunakan software SMS (Surface Water Modelling System) dengan sub-modul RMA-2 dan GFGEN. Perangkat ini diturunkan dari persamaan konservasi massa dan momentum yang diintegrasikan terhadap kedalaman (Wurjanto dan Ajiwibowo, 2020).

Persamaan konservasi massa:

$$
\frac{\partial h}{\partial t}+h\left(\frac{\partial u}{\partial x}+\frac{\partial v}{\partial y}\right)+u \frac{\partial h}{\partial x}+v \frac{\partial h}{\partial y}=0
$$

Persamaan konservasi momentum: $\operatorname{arah} \mathrm{x}$

$$
\begin{gathered}
h \frac{\partial u}{\partial t}+h u \frac{\partial u}{\partial x}+h v \frac{\partial u}{\partial y}-\frac{h}{\rho}\left(E_{x x} \frac{\partial^{2} u}{\partial x^{2}}+\right. \\
\left.E_{x y} \frac{\partial^{2} u}{\partial y^{2}}\right)+g h\left(\frac{\partial a}{\partial y}+\frac{\partial h}{\partial y}\right)+\frac{g u n^{2}}{\left(1,486 h^{1 / 6}\right)^{2}}+ \\
\left(u^{2}+v^{2}\right)^{1 / 2}-\zeta V_{a}{ }^{2} \sin \psi+ \\
2 h \omega v \sin \phi=0
\end{gathered}
$$

arah y

$$
\begin{gathered}
h \frac{\partial v}{\partial t}+h u \frac{\partial v}{\partial x}+h v \frac{\partial v}{\partial y}-\frac{h}{\rho}\left(E_{x x} \frac{\partial^{2} v}{\partial x^{2}}+\right. \\
\left.E_{x y} \frac{\partial^{2} v}{\partial y^{2}}\right)+g h\left(\frac{\partial a}{\partial y}+\frac{\partial h}{\partial y}\right)+\frac{g v n^{2}}{\left(1,486 h^{1 / 6}\right)^{2}}+ \\
\quad\left(u^{2}+v^{2}\right)^{1 / 2}-\zeta V_{a}^{2} \sin \psi+ \\
2 h \omega v \sin \phi=0
\end{gathered}
$$

dengan:

$h \quad$ : kedalaman perairan

$t$ : waktu

$u, v:$ komponen kecepatan arah $\mathrm{x}$ dan $\mathrm{y}$

$\rho \quad$ : kerapatan fluida 
$g \quad$ : percepatan gravitasi

$E$ : koefisien kekentalan turbulen, $\mathrm{xx}$ dalam arah normal terhadap bidang $\mathrm{x}$, yy dalam arah normal terhadap bidang $\mathrm{y}, \mathrm{xy}$ dan $\mathrm{yx}$ masing-masing berimpit dengan bidang $\mathrm{x}$ dan $\mathrm{y}$

$a$ : elevasi dasar perairan

$n \quad$ : koefisien kekasaran Manning

$\zeta \quad$ : koefisien tegangan geser angin empiris

$\mathrm{Va}$ : kecepatan angin

$\psi \quad$ : arah angin

$\omega$ : kecepatan rotasi bumi

$\phi \quad$ : posisi lintang geografis

\section{Verifikasi Model}

Verifikasi dilakukan dengan membandingkan hasil model dengan hasil pengukuran lapangan dengan uji statistik maupun perhitungan. Besar kesalahan yang terjadi dihitung dengan mencari nilai MRE (Mean Relatif Error). Perhitungan untuk mencari nilai tersebut adalah (Hatta, Thaha, dan Dharmawan, 2018):

$$
M R E=\left|\frac{h c-h o}{h o}\right| \times 100 \%
$$

dengan

$h c$ : besar nilai hasil model

ho : besar nilai hasil pengukuran lapangan

\section{Hasil dan Pembahasan}

\section{Model Sirkulasi Arus saat Muson Timur}

Model sirkulasi arus pada saat muson timur merupakan model sirkulasi arus pada kondisi musim kemarau. Pada wilayah kajian kondisi kemarau dengan jumlah curah hujan paling sedikit terjadi pada bulan juli. Pada kondisi ini dinilai pengaruh debit aliran sungai kurang mempengaruhi dibanding dengan musim hujan. Untuk mengetahui kondisi tersebut dapat dilihat pada Gambar 1 sampai 3.

Gambar 1 menunjukkan kondisi perairan Teluk Parepare pada saat menuju surut terendah dengan kecepatan arus rata-rata sebesar $0,015 \mathrm{~m} / \mathrm{s}$ dan elevasi muka air laut sebesar $1.046 \mathrm{~m}$. Kondisi ini terjadi pada time step 73 jam. Sementara terlihat jelas pada model kondisi perairan bagian utara Pelabuhan Nusantara kecepatan arus menujukkan adanya kecepatan arus yang relative lebih besar dibanding dengan lokasi bagian lainnya, yakni berkisar 0,069 - $0,129 \mathrm{~m} / \mathrm{s}$. Pergerakan arus serempak bergerak menuju laut dalam.

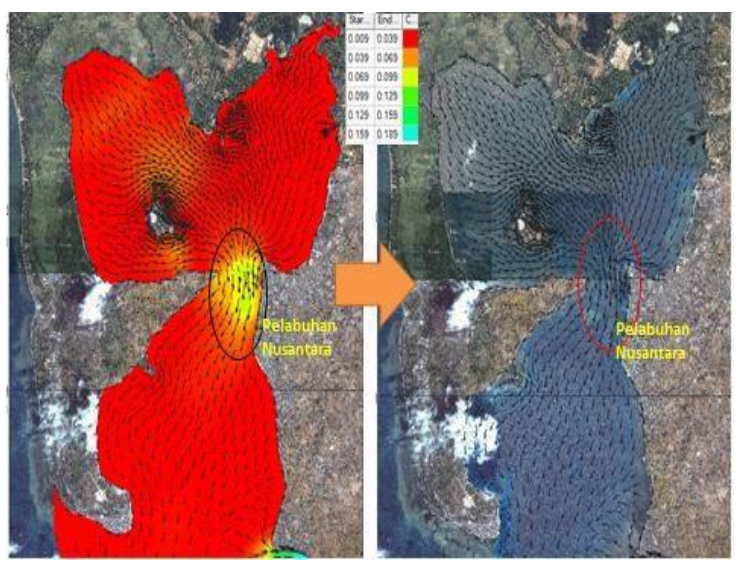

Gambar 1. Pola arus pada saat menuju surut terendah.

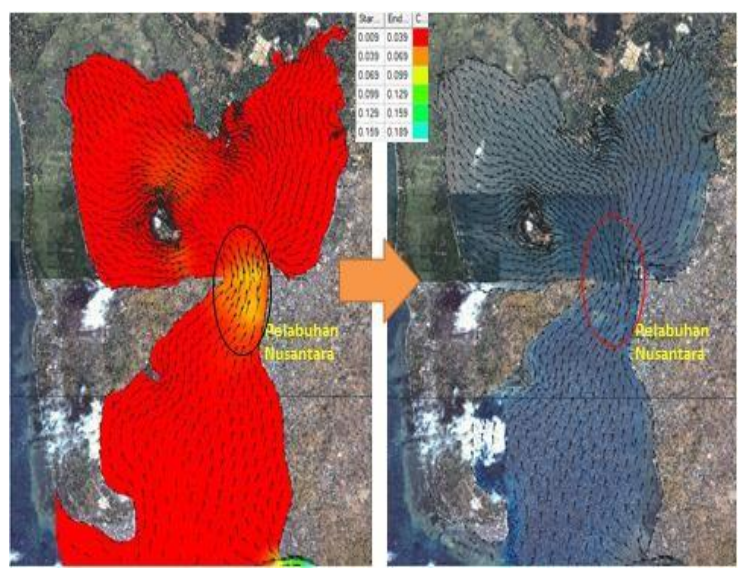

Gambar 2. Pola arus pada saaat menuju pasang maksimum.

Gambar 2 menunjukkan pola arus menuju pasang tertinggi terjadi pada time step 233 jam dengan kecepatan arus rata-rata 0,010 $\mathrm{m} / \mathrm{s}$. Kondisi ini terjadi dengan elevasi muka air laut sebesar $2.098 \mathrm{~m}$. Pada kondisi arus menuju pasang, kondisi perairan sekitar Pelabuhan Nusantara, vektor arus serentak bergerak menuju pantai. Pada kolam perairan Pelabuhan Nusantara. vektor arus dari laut dalam melewati mulut teluk dan terus bergerak serempak melewati kolam pelabuhan. Sementara pada bagian Utara Pelabuhan Nusantara 
terjadi percepatan arus dengan kecepatan rata-rata berkisar antara 0,039-0,099 $\mathrm{m}$.

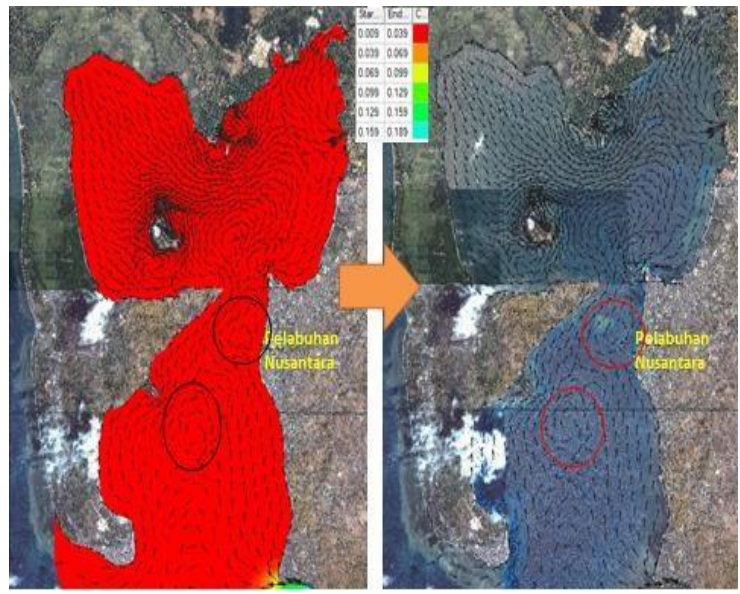

Gambar 3. Kondisi arus Pelabuhan ketika terjadi arus turbulensi pada musim timur.

Gambar 3 menunjukkan pada time step 123 jam dengan kecepatan arus rata-rata 0,030 $\mathrm{m} / \mathrm{s}$. Pada kondisi ini terjadi penurunan kecepatan sehingga menyebabkan gerakan arus turbulensi. Kondisi ini terjadi salah satunya dipengaruhi oleh perubahan topografi kedalaman laut. Sekitar $200 \mathrm{~m}$ ke arah barat dari Pelabuhan Nusantara terdapat cekungan kedalaman yang menyebabkan kondisi tertentu dapat menyebabkan adanya gerakan turbulensi/ rotasi air laut. Terutama terjadi pada kondisi surut, sifat dari fluida massa air akan mencari posisi yang lebih rendah dalam artian massa air akan bergerak menuju pada tingkat topografi kedalaman yang lebih tinggi. Pada kondisi terjadi ketika arus menuju surut dengan kecepatan yang relatif rendah berkisar $0,002-0,004$ $\mathrm{m} / \mathrm{s}$, selain itu pada saat ini terjadi pelepasan energi.

\section{Model Arus pada saat Muson Barat}

Pada kondisi muson barat atau musim hujan perairan Teluk Parepare sangat dipengaruh oleh aliran debit sungai, khususnya Sungai Karaja'e. Berdasarkan data Pemerintah Kota Parepare (2014) besarnya debit ratarata harian aliran maksimal mencapai $1084,25 \mathrm{~m}^{3} / \mathrm{s}$. Selanjutnya aliran tersebut dengan segalanya kondisinya dapat mempengaruhi kondisi hidrodinamika perairan Teluk Parepare khususnya kondisi pasang surut.

Gambar 4 menunjukkan kondisi perairan di sekitar Pelabuhan Nusantara dengan kecepatan rata-rata tertinggi sebesar 0,024 $\mathrm{m} / \mathrm{s}$. Kondisi ini terjadi pada time step 27 jam (hari ke-2) dengan elevasi muka air sebesar $1.696 \mathrm{~m}$. Setelah dua jam berikutnya elevasi muka air pasang mencapai puncak maksimum sebesar $2.257 \mathrm{~m}$ dengan kecepatan arus rata-rata menurun sebesar $0,017 \mathrm{~m}$. kondisi pada saat ini arus bergerak dari laut dalam menuju teluk dan pelabuhan. Di sebelah utara Pelabuhan Nusantara terdapat pergerakan arus dengan kecepatan yang relatif besar disbanding dengan kondisi lokasi lainnya, yakni pada daerah penyempitan Teluk Parepare. Kondisi ini di kedalaman $1-15$ $\mathrm{m}$.

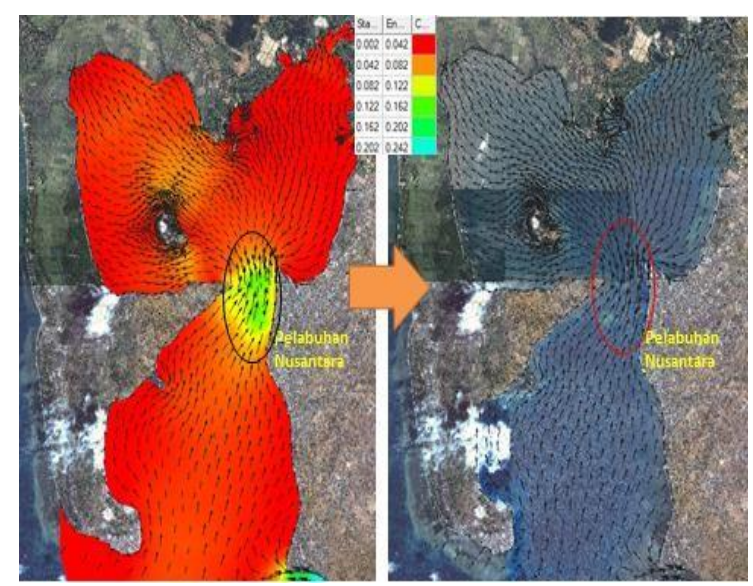

Gambar 4. Kondisi perairan pada saat arus menuju pasang dengan kecepatan arus rata-rata tertinggi.

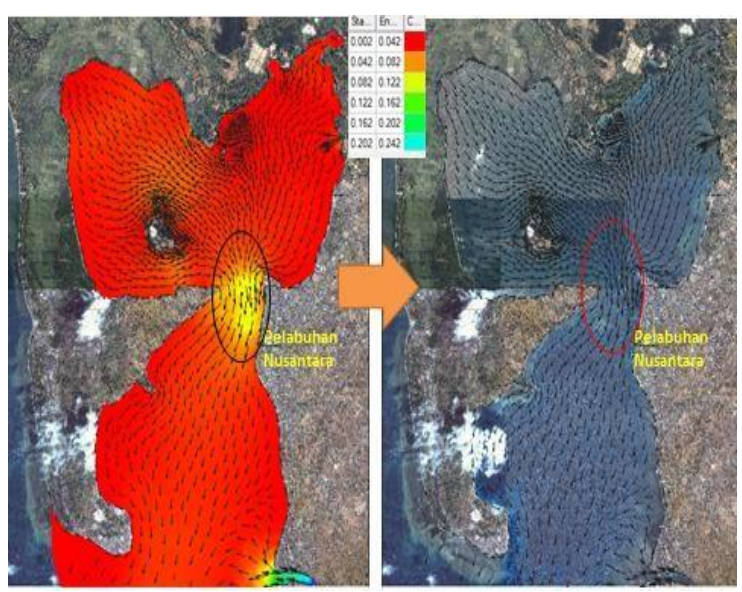

Gambar 5. Kondisi perairan pada saat menuju surut terendah dengan kecepatan arus rata-rata tertinggi. 
Gambar 5 menunjukkan kondisi perairan di sekitar Pelabuhan Nusantara pada saat air menuju surut terendah kecepatan rata- rata $0,016 \mathrm{~m} / \mathrm{s}$ dengan elevasi muka air laut $1.281 \mathrm{~m}$. Kondisi ini terjadi pada time step 45 jam (hari ke-2), yakni pada waktu surut kedua. Massa air laut bergerak terus menuju laut dalam dengan perlambatan kecepatan hingga $0,010 \mathrm{~m} / \mathrm{s}$ dengan durasi waktu selama 2 jam sehingga mencapai puncak surut paling rendah dengan elevasi sebesar $1.127 \mathrm{~m}$.

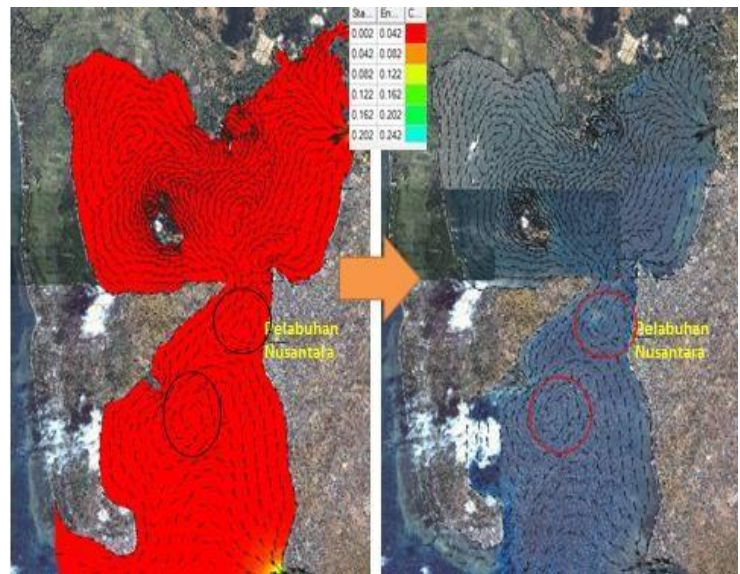

Gambar 6. Kondisi perairan pada saat terjadi arus turbulensi pada musim barat.

Pada Gambar 6 nampak bahwa terjadi arus turbulensi (pusaran arus) di bagian barat laut Pelabuhan Nusantara. Pusaran arus terjadi pada saat menuju surut setelah pasang dengan kecepatan yang relatif tinggi. Pada kondisi ini setelah kecepatan pasang sebesar $0,020 \mathrm{~m} / \mathrm{s}$, kemudian surut dengan kecepatan arus rata-rata sebesar $0,016 \mathrm{~m} / \mathrm{s}$ dengan elevasi muka air sebesar $1.280 \mathrm{~m}$.

Tabel 1 menunjukkan bahwa 1 kali siklus pasang surut selama 15 hari terjadi 9 kali terjadi arus berotasi. Kondisi terjadi ketika terjadi perubahan kecepatan arus rata-rata yang relatif signifikan, seperti pada kala ulang 254 jam. Pada kondisi ini terjadi arus surut dengan kecepatan sebesar $0,007 \mathrm{~m} / \mathrm{s}$. Selanjutnya pada kala ulang berikutnya pada saat arus menuju pasang terjadi penurunan kecepatan arus rata-rata sebesar $0,003 \mathrm{~m} / \mathrm{s}$. Kondisi ini juga terjadi kala ulang lainnya seperti yang nampak pada
Tabel 1. Arah sirkulasi arus yang acak dan berotasi kerap terjadi di area-area tertentu seperti area pendangkalan, jurang laut ataupun daerah diantara keduanya.

Tabel 1. Kondisi arus saat terjadi gerakan arus acak, pusaran, tubulen.

\begin{tabular}{cccc}
\hline $\begin{array}{c}\text { Time } \\
\text { Step } \\
\text { (jam })\end{array}$ & $\begin{array}{c}\text { Vrata- } \\
\text { rata } \\
(\mathrm{m} / \mathrm{s})\end{array}$ & $\begin{array}{c}\text { Elevasi } \\
(\mathrm{m})\end{array}$ & $\begin{array}{c}\text { Kondisi Pasang } \\
\text { Surut Air Laut }\end{array}$ \\
\hline 23 & 0,004 & 1.188 & Menuju pasang \\
30 & 0,004 & 2.245 & Menuju surut \\
37 & 0,005 & 2.262 & Menuju surut \\
103 & 0,004 & 2.131 & Menuju surut \\
164 & 0,004 & 1.924 & Menuju pasang \\
194 & 0,003 & 1.563 & Menuju pasang \\
213 & 0,003 & 1.835 & Menuju pasang \\
245 & 0,003 & 1.872 & Menuju pasang \\
254 & 0,003 & 1.197 & Menuju pasang \\
\hline
\end{tabular}

Pada kondisi daerah pendangkalan terjadi rotasi arus. Hal ini sesuai dengan Wisha, Husrin, dan Prihantono (2015) bahwa semakin ke atas gerakan arus mulai di pengaruhi oleh faktor lain, yaitu angin dan pasang surut. Gerakan arus menjadi semakin cepat di permukaan dan sudah tidak ada lagi hambatan seperti gesekan dasar dan densitas air laut.

\section{Verifikasi Hasil Model}

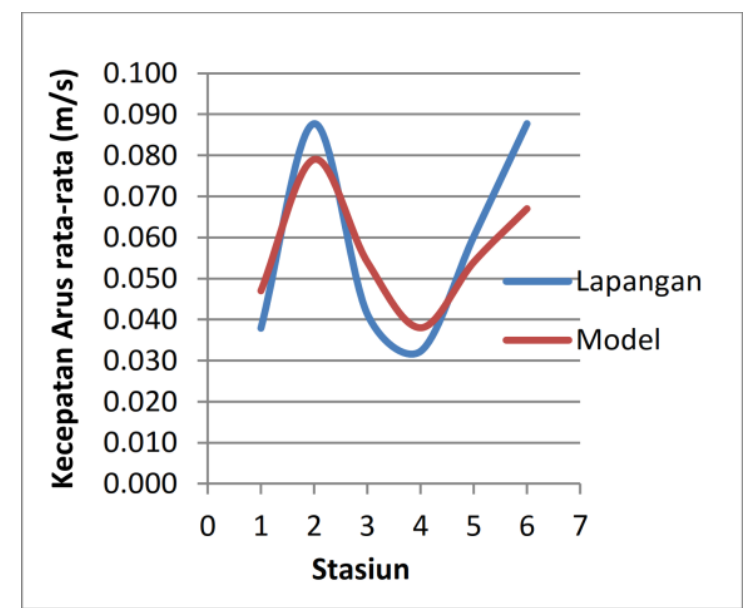

Gambar 7. Kalibrasi data lapangan dan hasil model.

Hasil pengukuran kecepatan arus rata-rata secara langsung untuk verifikasi model diambil pada lokasi pengamatan. Kecepatan arus rata-rata yang tidak digunakan sebagai kondisi batas pemodelan, yaitu lokasi pengukuran di 
sekitar Pelabuhan Nusantara dengan kedalaman $2-10 \mathrm{~m}$. Hasil perbandingan antara pengukuran kecepatan arus rata-rata secara langsung di perairan Pelabuhan Nusantara dengan hasil simulasi disajikan pada Gambar 7.

Gambar 7 menunjukkan kecepatan arus rata-rata hasil simulasi memberikan hasil yang tidak berbeda secara signifikan. Sehingga diasumsikan validitas parameterparameter model kontrol serta referensi kondisi batas kecepatan arus rata-rata yang diaplikasikan pada pemodelan telah mendekati kebenaran sesuai kondisi pengukuran lapangan.

Verifikasi kecepatan arus dilakukan dengan mengambil 6 stasiun daerah cuplik. Setiap stasiun diambil pada posisi dan kedalaman yang relatif sama. Perhitungan nilai error disajikan pada Tabel 2.

Tabel 2. Verifikasi model untuk kategori kecepatan arus.

\begin{tabular}{cccc}
\hline St & $\begin{array}{c}\text { Lapangan } \\
(\mathrm{m} / \mathrm{s})\end{array}$ & $\begin{array}{c}\text { Model } \\
(\mathrm{m} / \mathrm{s})\end{array}$ & $\begin{array}{c}\text { Presentase } \\
(\%)\end{array}$ \\
\hline 1 & 0,036 & 0,043 & 0,2408 \\
2 & 0,078 & 0,077 & $-0,0994$ \\
3 & 0,042 & 0,051 & 0,3068 \\
4 & 0,031 & 0,032 & 0,178 \\
5 & 0,062 & 0.053 & $-0,1036$ \\
6 & 0,087 & 0.062 & $-0,2362$ \\
& MRE & 0,04773 & 4,7733 \\
\hline
\end{tabular}

\section{Kesimpulan}

Karakteristik kondisi arus pada saat musim barat (hujan) kecepatan arus lebih besar dan lebih fluktuatif (tidak stabil) dibandingkan dengan kecepatan arus rata-rata pada musim timur (kemarau). Sementara untuk kondisi gelombang, Pelabuhan Nusantara di Teluk Parepare dominan dipengaruhi oleh angin dari arah barat. Arah gelombang dominan bergerak ke arah timur laut dengan tinggi gelombang rata-rata $0,20 \mathrm{~m}$ sampai $0,40 \mathrm{~m}$.

\section{Ucapan Terima Kasih}

Ucapan terima kasih kepada pihak konsultan yang telah memberikan data hasil survey lapangan berupa data bathimetri (kedalaman) dan data pasang surut. Sehingga penelitian ini bisa terselesaikan dengan baik.

\section{Daftar Pustaka}

Hatta, M.P., Thaha, A., dan Dharmawan, A. 2018. Pengaruh Kondisi Hidrodinamika Pantai Tarowang Terhadap Penentu Tipe Pengaman Pantai. Jurnal Keteknikan dan Sains. 1(2), pp.69-73. https://journal.unhas.ac.id/index.ph p/juteks/article/view/5345

Pemerintah Kota Parepare. 2014. PENYUSUNAN RPI2-JM TAHUN $2015 \quad 2019$. https://sippa.ciptakarya.pu.go.id/

Wisha, U.J., Husrin, S., dan Prihantono, J. 2015. Hydrodynamics Banten Bay During Transitional Seasons (August-September). Indonesian Journal of Marine Sciences. 20(2), pp.101-112. https://10.14710/ik.ijms.20.2.101112

Wisha, U.J., dan Heriati. A. 2016. Analisis Julat Pasang Surut (Tidal Range) dan Pengaruhnya Terhadap Sebaran Total Sedimen Tersuspensi (TSS) di Perairan Teluk Pare. Jurnal Kelautan. 9(1), pp.23-31. https://doi.org/10.21107/jk.v9i1.10 66

Wurjanto, A., dan Ajiwibowo, H. 2020. Analisis Hidrodinamika di Perairan Lemong, Kabupaten Barat, Provinsi Lampung Menggunakan Piranti Surface-Water Modeling System. Rekayasa. 13(2), pp.154-163. https://doi.org/10.21107/rekayasa.v $\underline{13 \mathrm{i} 2.6480}$

*) Artikel ini telah dipresentasikan di Seminar Nasional Geofisika 2019 yang 
dilaksanakan oleh Dept. Geofisika FMIPA Universitas Hasanuddin di Science Building FMIPA Universitas Hasanuddin pada tanggal 26 Oktober 2019. 